\title{
Estrous detection intensity and accuracy and optimal timing of insemination with automated activity monitors for dairy cows
}

\author{
C. N. S. LeRoy, ${ }^{*}$ J. S. Walton, $\dagger^{1}$ and S. J. LeBlanc ${ }^{* 2}$ \\ *Department of Population Medicine, and \\ †Department of Animal Biosciences, University of Guelph, Ontario, N1G 2W1, Canada
}

\begin{abstract}
The objectives of this observational study were to assess the ability of automated activity monitoring (AAM) to detect estrus for first insemination, the accuracy of detection, and the optimum interval from the estrus alert from the AAM system to insemination. Four commercial farms using 1 of 2 commercial AAM systems were studied over 1 yr. Cows were inseminated between 55 and $80 \mathrm{~d}$ in milk (DIM) based on AAM only, then by a combination of AAM and timed artificial insemination (AI). Blood progesterone was measured in 1,014 cows at wk 5, 7, and 9 postpartum; purulent vaginal discharge (PVD) was assessed at wk 5; and lameness and BCS at wk 7. Overall, AAM detected $83 \%$ of cows in estrus by 80 DIM. Cows that had 3 serum progesterone $<1 \mathrm{ng} / \mathrm{mL}$, had PVD, or were both lame and had BCS $\leq 2.5$ has lesser odds of being detected in estrus by 80 DIM (62, 68, and 53\%, respectively). Blood samples were collected on the day of $445 \mathrm{AI}$ based on AAM and 323 timed AI. The proportion of cows not in estrus (progesterone $>1 \mathrm{ng} / \mathrm{mL}$ ) on the day of AI was similar between AAM $(4 \pm 1.8 \%)$ and timed AI $(3 \pm 1.2 \%)$. Managers elected, based on subjective criteria, not to inseminate $17 \%$ of cows for which an AAM estrus alert was issued, of which $43 \%$ were not in estrus. Activity data were extracted from AAM software for 1,399 AI. Onset of estrus was calculated using the same or similar data processing criteria as the AAM system. Producers recorded the time of AI. The interval from onset of estrus to AI was categorized as 0 to 8,8 to 16 , or 16 to $24 \mathrm{~h}$. We found no effect of AAM system on the probability of pregnancy per AI, but noted an interaction of interval with parity. For multiparous cows, the probability of pregnancy per AI was $31 \%$, which did not differ with the interval to AI. For primiparous cows, the odds of pregnancy were greater if AI occurred
\end{abstract}

Received July 16, 2017.

Accepted October 24, 2017.

${ }^{1}$ Deceased.

${ }^{2}$ Corresponding author: sleblanc@uoguelph.ca
0 to $8 \mathrm{~h}(49 \%)$ than 8 to $16(36 \%)$ or 16 to $24 \mathrm{~h}(31 \%)$ after the estrus alert from the AAM. Automated activity monitoring can detect estrus for first AI in just over the length of 1 estrous cycle for over $80 \%$ of cows, but the remainder would likely require intervention for timely insemination. For multiparous cows, performing AI based on AAM once per day would not affect pregnancy per AI, but for primiparous cows AI within $8 \mathrm{~h}$ of the onset of estrus may be advantageous.

Key words: accelerometer, precision technology, reproduction management

\section{INTRODUCTION}

Inseminating cows in a timely manner is important for efficient dairy production management (Walker et al., 1996). Automated activity monitor (AAM) systems are useful tools for detection of estrus (Fricke et al., 2014), and producers who have installed AAM systems report satisfaction with their performance (Michaelis et al., 2013). However, many environmental and metabolic variables can have negative effects on the ability of AAM to identify cows in estrus. Optimizing the timing of insemination relative to ovulation is important for pregnancy (Roelofs et al., 2006). The practical obstacle is identifying when ovulation will occur with sufficient precision. The spermatozoa take approximately $8 \mathrm{~h}$ to reach the isthmus of the oviduct, and by 12 to $24 \mathrm{~h}$ few spermatozoa remain in the reproductive tract (Hawk, 1987); providing sufficient time for sperm capacitation is also important for optimal timing of AI. The time of ovulation relative to signs of estrus is variable among cows, making identifying the optimal time of insemination a challenge (Roelofs et al., 2006).

In a reproductive program that uses activity monitors for heat detection, a cow must have estrus with an associated increase of activity for insemination to occur. Additionally, not specific to estrus detected by AAM, failure of ovulation is reported to occur $7 \%$ of the time in lactating dairy cows, more so under heat stress (López-Gatius et al., 2005). To try to capture estrus as accurately as possible, various accelerometers 
and data processing algorithms have been developed to detect relevant changes in activity. A review (SaintDizier and Chastant-Maillard, 2012) found that the efficiency of estrus detection (number of cows detected in estrus relative to the number of cows in estrus) of AAM systems is generally greater than $80 \%$. However, the reported positive predictive value of (i.e., the accuracy of the alerts) of these systems varied from 20 to $100 \%$ depending on the threshold and algorithm used (Saint-Dizier and Chastant-Maillard, 2012). The extent to which activity monitors might be relied upon to detect cows in estrus for first insemination has not been quantified.

The gold standard for estrus is a cow that is standing to be mounted, has a dominant follicle that subsequently ovulates, and has low a concentration of progesterone (P4) in serum or milk. If a cow has high P4 while displaying signs of estrus, including increased activity, it can be considered as a falsely identified estrus (Aungier et al., 2012). However, a cow with a low circulating concentration of $\mathrm{P} 4$ cannot be assumed to be in estrus because it is possible that the cow is anovular or may be in proestrus or metestrus. Holman et al. (2011) found that $93.5 \%$ of the estrus events detected with activity monitors were associated with milk P4 below $0.2 \mathrm{ng} /$ $\mathrm{mL}$, meaning that there were few false-positives.

Although the time from onset of estrus-based increased activity to ovulation is quite consistent (29 to 30 h; reviewed by Roelofs and van Erp-van der Kooij, 2015), the optimal interval from activity passing a prescribed threshold in the AAM system software to insemination is less clear. Maatje et al. (1997) found that the highest probability of pregnancy per AI (P/ AI) was achieved 6 to $17 \mathrm{~h}$ after an increase of activity using pedometers. In a large field study using 1 commercial AAM system, Stevenson et al. (2014) found a difference in the optimal interval from onset of estrus (signaled the AAM system) to insemination for primiparous cows compared with multiparous cows, such that they should be inseminated 13 to 16 or 0 to $12 \mathrm{~h}$ after passing the activity threshold, respectively. A recent review (Roelofs and van Erp-van der Kooij, 2015) supports that the optimal interval from onset of estrus based on AAM to AI is 5 to $17 \mathrm{~h}$.

The first objective of the current study was to determine the proportion of cows detected in estrus by AAM alone by 80 DIM and to evaluate the effects of BCS, milk yield, anovular status, lameness, or having purulent vaginal discharge (PVD) on this outcome. The second objective was to evaluate the accuracy of activity monitors (correct identification of cows with low P4 at the time of insemination) and to compare that to timed AI. Our third objective was to assess the association between producer-recorded signs of estrus for cows detected in estrus by AAM and the probability of pregnancy to that AI. The final objective was to determine the time interval from activity monitor estrus alert to insemination associated with the highest $\mathrm{P} / \mathrm{AI}$. Our hypothesis was that cows would have the highest probability of pregnancy if bred within $16 \mathrm{~h}$ after the activity alert.

\section{MATERIALS AND METHODS}

\section{Farms and Monitoring Systems}

Four farms within a $1 \mathrm{~h}$ drive of the University of Guelph (Ontario, Canada) were enrolled in this observational study, which was conducted from May 2014 to August 2015. The herds were a purposive sample of herds with AAM systems that were enrolled in DHIA and were willing to collect data and participate in the study. Two of the farms had the AfiAct (Afimilk, Kibbutz Afikim, Israel) leg-mounted activity monitor system and were milked 3 times a day. The other 2 farms had neck-mounted Heatime (SCR Engineers, Netanya, Israel) activity monitors, 1 with Heatime $\mathrm{HR}$ and 1 with Heatime Dataflow; both of these herds milked 2 times per day. All of the herds used DairyComp305 (DC305; Valley Ag Software, Tulare, CA) as the herd management software. The farms involved in this study are described in Table 1 . The data in Table 1 on herd annual reproductive performance were all calculated in DairyComp 305 using a standard voluntary waiting period of 50 DIM. All farms had sand-bedded freestall barns and the herd size ranged from 100 to 400 lactating cows.

During the study, enrolled farms continued with the reproduction management program that they had in place. For all herds, insemination started at 55 DIM and was done exclusively based on estrus detection by AAM until 80 DIM, after which both estrus detection based on activity monitor alerts and timed artificial insemination (TAI) protocols were employed. Insemination was generally performed twice daily, but for each insemination producers were asked to record the date, cow identification, the time of insemination, and whether the insemination was based on an activity signal or a TAI protocol. Data were collected from DC305 and from the software of the activity monitors during weekly farm visits. Data on inseminations and pregnancy outcomes were extracted from DC305 and exported to Microsoft Excel (Microsoft Corp., Redmond WA).

Farms were visited once weekly for sample collection and to retrieve data from DC305. Blood samples were collected from all cows via the coccygeal vessels into an evacuated tube without anticoagulant (Vacutainer, Becton, Dickinson and Co., Franklin Lakes, NJ) at wk 5 
(32-38 DIM), 7 (46-52 DIM), and 9 (60-66 DIM) postpartum. Blood samples were also collected from cows that were inseminated or were flagged by the activity monitor as being in estrus on the day of the weekly farm visit. These samples were allowed to clot and then transported to the laboratory and centrifuged at 1,500 $\times g$ for $15 \mathrm{~min}$ at $20^{\circ} \mathrm{C}$. The serum was removed from the sample and frozen at $-20^{\circ} \mathrm{C}$ for later analysis of $\mathrm{P} 4$ concentration. Cows were examined for PVD using the Metricheck device (Simcrotech, Hamilton, New Zealand) at wk 5 postpartum. Discharge was evaluated using a 0 to 3 scale similar to Leutert at al. (2012). A cow with a score of 2 or greater was considered to be positive for PVD. At wk 7 postpartum, BCS was assigned and lameness scoring was performed. The BCS was based on a 5-point scale (Edmonson et al., 1989), and a cow was considered thin if BCS was $\leq 2.5$ at wk 7 of lactation. The locomotion score was also on a 5-point scale (Sprecher et al., 1997), and a cow scoring $\geq 3$ was considered to be lame. The majority of scoring was performed by the first author and assistants were trained and verified to have similar scoring when necessary. Milk yield and percent fat and protein were also recorded for the first 2 DHIA tests of the lactation (test 1 mean $=23 \pm 12.5 \mathrm{DIM}$, test 2 mean $=59 \pm$ 13.8 DIM) from CanWest DHI (Guelph, ON, Canada).

The serum samples taken from all cows at wk 5, 7, and 9 postpartum and from the subsample of cows on the day of AI were thawed and $\mathrm{P} 4$ was measured using the Ovucheck Plasma (Biovet, Saint-Hyacinthe, QC, Canada) ELISA test. This 96-well test has a range of quantification from 0.55 to $10.45 \mathrm{ng} / \mathrm{mL}$ and has been validated for accuracy in cattle (Broes and LeBlanc, 2014). Cows were considered to be anovular if all samples from wk 5, 7, and 9 postpartum had $\mathrm{P} 4<1.0 \mathrm{ng} /$ $\mathrm{mL}$ (Stevenson et al., 2006). For samples on the day of AI, cows with serum P4 $>1.0 \mathrm{ng} / \mathrm{mL}$ were determined not to be in estrus at insemination.
Managers were asked to record details of insemination on standardized forms: time of insemination, whether AI was based on AAM signal or TAI, the technician who performed the AI, the ease of insemination, and whether any of mounting or standing to be mounted, increased activity, decrease in milk production, or presence of mucus discharge were observed before or during AI.

The raw activity recorded by the AfiAct activity tags was transmitted to the farm computer when the cow entered the parlor at each of the 3 daily milkings (farms A and D). At this time, the cows that had a deviation in activity that surpassed the threshold for estrus would be flagged on the AfiFarm software and put on a list of cows to inseminate. The activity value that was produced by the system at each milking was an average of the hourly activity for the time between the current milking and the one preceding it (i.e., average steps per hour for each 8-h session). Before the first milking of each day, a data back-up file was produced and automatically saved on the farm computer with the 3 activity values from the previous day. At the end of the study, the daily files were merged to form a timeline of activity for each cow. These activity data where then used to identify the 8-h period in which a cow crossed the threshold of activity and was flagged as in estrus by the system. The raw activity data did not include a notation of the period in which estrus was first signaled. To recreate when a cow was flagged in estrus the average and standard deviation of the activity of the $10 \mathrm{~d}$ before each AI was created. To be flagged as in estrus, the activity value must reach a threshold. According to the system software, the threshold value varied with the baseline average number of steps a cow took per hour (as seen in Supplemental Table S1; https://doi.org/10.3168/jds.2017-13505). Once a cow crossed the threshold, the onset was considered to be the time within an 8-h data collection period that the

Table 1. Descriptive information for commercial dairy herds in Ontario, Canada, enrolled in an observational study on the performance of automated activity monitor systems for reproductive management

\begin{tabular}{|c|c|c|c|c|}
\hline Descriptor & Herd A & Herd B & Herd C & Herd D \\
\hline Average herd size (milking cows, no.) & 352 & 160 & 94 & 250 \\
\hline Herd average $305 \mathrm{ME}^{1}(\mathrm{~kg})$ & 14,474 & 12,541 & 12,354 & 12,366 \\
\hline Stage of pregnancy diagnosis (d after AI) & $30-40$ & $42-60$ & $35-47$ & $30-40$ \\
\hline \multicolumn{5}{|l|}{ Herd annual reproductive performance } \\
\hline 21-d pregnancy rate (\%) & 23 & 15 & 25 & 31 \\
\hline 21 -d insemination rate $(\%)$ & 67 & 67 & 62 & 74 \\
\hline Conception risk (\%) & 33 & 21 & 39 & 44 \\
\hline Number of sires used for AI during the study & 80 & 90 & 37 & 22 \\
\hline Milking frequency per day & 3 & 2 & 2 & 3 \\
\hline Activity monitor system & AfiAct $^{2}$ & Heatime $^{3}$ & Heatime & AfiAct \\
\hline
\end{tabular}

${ }^{1} 305$-d mature-equivalent milk.

${ }^{2}$ AfiMilk, Kibbutz Afikim, Israel.

${ }^{3} \mathrm{SCR}$, Madison, WI. 
estrus signal appeared on the computer and could be viewed by the manager, which for both of the enrolled herds with AfiAct was considered to be 0600, 1400, or $2200 \mathrm{~h}$ (i.e., at the end of each milking, at which time data were transferred from the leg-mounted accelerometer and the list of alerts made available on the farm computer).

The SCR system produced values for activity in 2-h intervals. The computer-based Dataflow system made daily reports of the previous day's raw activity, producing twelve 2-h intervals of each day for each cow. These daily files were then merged to produce an activity timeline for each cow. The standalone Heatime HR system had a back-up option to extract all the raw activity for up to $1 \mathrm{yr}$. This file was converted to a Microsoft Excel file by the Heatime Batch tool, which produced the raw activity timeline for each cow for each day in 2-h blocks. To calculate when a cow crossed an activity threshold for estrus, activity change, which is a proprietary calculation from SCR, is required. This value was unavailable for the Heatime Dataflow system, so it was recreated using a calculation provided by SCR that created a value which is a close approximation of the proprietary algorithm. For uniformity, this calculation was used for both of the SCR herds. It was calculated by first taking the average of the previous 10 $\mathrm{h}$, including the current 2 -h value, to create the 10 - $\mathrm{h}$ average. Then, taking the mean of the 10-h average of the same time period of the past $7 \mathrm{~d}$, the week average was created. The standard deviation was then taken of the 7 values in the week average to create the week standard deviation. A logical test was then performed: if the week standard deviation divided by the week average was $<0.05$, then MinStd was equal to the week average multiplied by 0.05 ; if not, the MinStd was equal to the week standard deviation. Another logical test was performed: if the week standard deviation divided by the week average was greater than 0.2 , then the NewStd was equal to week average multiplied by 0.2; if not, NewStd was equal to MinStd. The activity change value was then calculated by subtracting the week average from the 10-h average, dividing that by NewStd, and then multiplying by 5 . Once the activity change was calculated, it, along with the raw activity, was processed using a Microsoft Excel macro that was developed and validated by University of British Columbia to identify the 2 -h periods when the onset of estrus activity occurred (Madureira et al., 2015).

The recreated times of onset of estrus from both systems were then merged with the insemination dates and times that were recorded by the producers. The interval between the time of estrus signal from the AAM and insemination was then calculated. To be comparable between systems, the intervals from estrus alarm to AI were classified as 0 to 8,8 to 16 , or 16 to $24 \mathrm{~h}$. Inseminations that occurred before or $>24 \mathrm{~h}$ after the AAM alert were not included in the analysis of the timing of AI.

\section{Statistical Analysis}

Data for AI dates, breeding codes (i.e., based on AAM signal or timed AI protocol), pregnancy diagnosis, and culling were extracted from DC305 and the raw activity data was extracted from the automated activity systems. The data were then exported into Microsoft Excel for all enrolled animals. The statistical analyses were performed in SAS (version 9.4, SAS Institute Inc., Cary, NC). Univariable associations of all variables with the relevant outcomes and interactions were screened using the FREQ procedure and variables with a $P$-value $<0.2$ were offered to the 4 multivariable mixed logistic regression models (GLIMMIX procedure in SAS).

Model for Detection of Estrus by 80 DIM. The variables parity (first, second, or third or greater), milk yield, percent fat and percent protein at first and second DHIA test, being anovular, positive for PVD, low $\mathrm{BCS}$, and the interactions between them were tested for their association with being detected in estrus and inseminated by 80 DIM. When building the model, the variables that passed the screening and were offered to the model were (1) being anovular, (2) positive for PVD, (3) parity, and the interactions of (4) low BCS with lameness, (5) positive PVD with low BCS, (6) being anovular with being lame, (7) being anovular with low BCS, (8) parity with being anovular, (9) parity with low BCS, (10) parity with being lame, and (11) parity with PVD. A random effect for farm was included to account for the unmeasured sources of variability between herds and correlation of cows within a herd.

Model for Accuracy of Detection. The outcome variable was a serum $\mathrm{P} 4<1 \mathrm{ng} / \mathrm{mL}$ on the day of insemination. The predictor variable was the basis of insemination (an activity monitor alert or based on a timed AI protocol) or being from a cow that was flagged by the activity monitor but not inseminated. Both farm and cow were included as random effects.

Model for Observed Sign of Estrus. The variables (1) technician who performed the AI, (2) the ease of insemination, (3) observed mounting, (4) observed being mounted, (5) observed increase in activity, (6) observed decrease in milk production, and (7) observed presence of mucus discharge were screened for association with pregnancy to the AI. Decrease in milk production, presence of mucus discharge, and the interaction between 
then were offered the model. Both farm and cow were included as random effects.

Model for Optimal Time of Insemination. The variables farm, activity monitor system (Afimilk or SCR), parity, time to insemination ( 0 to 8,8 to 16 , or 16 to $24 \mathrm{~h}$ ) and the interactions among them were tested with pregnancy as the outcome for each AI. The variables time to insemination, parity, and the interaction of time to insemination with parity passed the screening and were offered to the model. Farm was included as a random effect. The unit of analysis was the insemination and, because some but not all cows contributed more than $1 \mathrm{AI}$, cow (nested within farm) was also included as a random effect.

Sample Size. Sample size was calculated based on estimating the intensity of estrus detection by AAM by 80 DIM within \pm 3 points with $95 \%$ confidence and $80 \%$ power. We assumed that the proportion of cows detected would be $70 \%$, so the sample size required was $>897$ cows (WINPEPI; Abramson, 2011).

\section{RESULTS}

\section{Detection of Estrus by 80 DIM}

There were 1,014 cows with blood samples from wk 5,7 , and 9 . Of these cows, $17 \%$ were not identified between 55 and 80 DIM as being in estrus by AAM. The prevalence of cows being anovular, positive for PVD, having low BCS, and lame was 9, 14, 9, and 15\%, respectively. In preliminary analyses, first-parity cows had an increased incidence of PVD and cows in parity 3 and greater had a higher prevalence of lameness, $\mathrm{BCS} \leq 2.5$, and being anovular. However, we found no interactions of these variables in the in the final model of detection of estrus by AAM by 80 DIM.

Cows that were anovular, positive for PVD, multiparous, or cows that had both low BCS and were lame had decreased odds of being detected in estrus by the AAM system and inseminated by 80 DIM (Table 2). We found no associations of milk yield, percent fat, or percent protein at first or second DHIA test with the odds of being detected in estrus by AAM by 80 DIM. Though the interaction between being anovular and being lame was not significant in the final model, $18 \%$ of the 149 lame cows were anovular compared with $7 \%$ of nonlame cows. The interaction between being anovular and having low BCS was also not significant in the final model, but $26 \%$ of cows with a BCS of $\leq 2.5$ were anovular and $7 \%$ of cows with a BCS $>2.5$ were anovular.

The third blood sample to determine if a cow was anovular was taken at $63 \pm 3$ DIM; therefore, a window existed for a cow to start to cycle and be inseminated by 80 DIM but still be considered as anovular. Of the 87 cows classified as anovular, $28(32 \%)$ were inseminated between 67 and 79 DIM, and were therefore identified as anovular, but apparently began to cycle after the last blood sample. Thirty anovular cows (34\% of the anovular cows or $4 \%$ of cows inseminated by 80 DIM)

Table 2. Final mixed logistic regression model, accounting for the random effect of farm, of variables associated with being inseminated between 55 and 80 DIM based only on detection of estrus by automated activity monitors without intervention in 1,014 cows in 4 herds

\begin{tabular}{|c|c|c|c|c|c|c|c|c|}
\hline Variable & Class & $\mathrm{n}$ & $\mathrm{OR}^{1}$ & $\begin{array}{c}\text { Predicted } \\
\text { detection }{ }^{2}(\%)\end{array}$ & $\beta$ & $\mathrm{SE}$ & $95 \%$ CI & $P$-value \\
\hline \multirow[t]{2}{*}{ Anovular ${ }^{3}$} & Yes & 87 & 0.38 & 62 & 0.97 & 0.27 & $0.23-0.64$ & $<0.001$ \\
\hline & No & 927 & Referent & 81 & - & - & - & - \\
\hline \multirow[t]{2}{*}{$\mathrm{PVD}^{4}$} & Yes & 140 & 0.66 & 68 & 0.41 & 0.24 & $0.42-1.05$ & 0.08 \\
\hline & No & 871 & Referent & 76 & - & - & - & - \\
\hline \multirow[t]{2}{*}{ Low $\mathrm{BCS}^{5}$} & Yes & 88 & 0.76 & 70 & 0.75 & 0.45 & $0.42-1.36$ & 0.35 \\
\hline & No & 923 & Referent & 75 & - & - & - & - \\
\hline \multirow[t]{2}{*}{ Lame $^{6}$} & Yes & 149 & 0.40 & 63 & 1.38 & 0.53 & $0.23-0.72$ & 0.002 \\
\hline & No & 862 & Referent & 81 & - & - & - & - \\
\hline \multirow[t]{3}{*}{ Parity } & 1 & 327 & Referent & 78 & -0.43 & 0.22 & $0.42-1.01$ & 0.06 \\
\hline & 2 & 221 & 0.62 & 68 & 0.059 & 0.23 & $0.68-1.66$ & 0.80 \\
\hline & $3+$ & 456 & 0.65 & 70 & - & - & - & - \\
\hline \multirow[t]{4}{*}{ Low BCS and lame } & Not low BCS and not lame & 804 & & 79 & 0.95 & 0.58 & & 0.11 \\
\hline & Low BCS and not lame & 58 & & 71 & & & & \\
\hline & Not low BCS and lame & 119 & & 82 & & & & \\
\hline & Low BCS and lame & 30 & & 53 & & & & \\
\hline
\end{tabular}

\footnotetext{
${ }^{1} \mathrm{OR}=$ odds ratio.

${ }^{2}$ Model-predicted probability of detection in estrus by 80 DIM.

${ }^{3}$ Anovular at wk 9; serum $\mathrm{P} 4<1 \mathrm{ng} / \mathrm{mL}$ at wk 5, 7, and 9 .

${ }^{4} \mathrm{PVD}=$ purulent vaginal discharge; score $\geq 2$ (i.e., muco-purulent).

${ }^{5} \mathrm{BCS} \leq 2.5$.

${ }^{6}$ Lameness-locomotion score of $\geq 3$ (Sprecher et al., 1997).
} 
Table 3. Prevalence of signs of estrus observed by producers at time of insemination based on a signal from an activity monitor system ( $\mathrm{n}=2,060$ AI from 898 cows on 4 farms)

\begin{tabular}{lc}
\hline Estrus signal & Prevalence (\%) \\
\hline Observation of increased activity (visual) & 76 \\
Observation of mounting & 44 \\
Observation of standing to be mounted & 43 \\
Observation of mucus discharge during AI & 25 \\
Decreased milk yield noted during the preceding milking & 14 \\
Easy insemination (ease of passage of the AI catheter through the cervix) & 98 \\
\hline
\end{tabular}

were inseminated before 66 DIM; therefore, those cows would have been inseminated based on a false-positive alert.

\section{Accuracy of Detection}

Over the course of the study, 919 blood samples were taken from cows that were being inseminated or had been flagged as in estrus by the activity monitor on the day of the weekly farm visit. Of these, 445 samples were from inseminations based on activity, 323 were timed inseminations, and 148 were samples taken from cows that were flagged that day by the AAM system but not inseminated. Of the 148 cows not inseminated, 36 were not inseminated because they had not passed the voluntary waiting period of 55 DIM, and 23 samples were from cows designated not to be inseminated (do not breed). The reason for not inseminating the remaining 89 cows was unknown.

Of the samples taken on day of insemination that were classified as having low progesterone $(<1 \mathrm{ng} / \mathrm{mL})$, $98.7 \%$ had progesterone classified at the lower limit of quantification $(0.55 \mathrm{ng} / \mathrm{mL})$. We found no difference $(P=0.35)$ in the odds of a cow having high $\mathrm{P} 4$ between those inseminated based on activity and those inseminated based on timed AI $(3 \pm 1.2$ and $4 \pm 1.8 \%$ of samples had $\mathrm{P} 4>1 \mathrm{ng} / \mathrm{mL}$, respectively). Cows that were signaled as in estrus by AAM but not inseminated for an unknown reason had higher $(P<0.0001)$ proportion of samples with high P4 $(43 \pm 11.2 \%)$ than samples from inseminations based on AAM or TAI.

Considering all animals flagged as being in estrus by the AAM system $(\mathrm{n}=538)$, both inseminated and not inseminated, $9 \pm 2.0 \%$ had serum $\mathrm{P} 4>1 \mathrm{ng} / \mathrm{mL}$. This was greater $(P=0.02)$ than the proportion among cows inseminated based on TAI $(4 \pm 1.8 \%)$.

\section{Observed Signs of Estrus}

For 2,849 inseminations, observed signs of estrus were recorded by the producers on standardized forms. Of these inseminations, 2,151 (76\%) were based on an activity monitor alert and $698(24 \%)$ were based on TAI. There were 2,060 activity-based inseminations and 667
TAI that were fully recorded by the producer both on the standardized forms and in the herd management software.

For these 2,060 inseminations that were based solely on an AAM alert (for all inseminations, first or repeated), $640(31 \%)$ resulted in a diagnosed pregnancy. The signs of estrus that were observed by the producers are presented in Table 3. Observation of increased activity, mounting behavior, standing to be mounted, and ease of insemination were not associated with the probability of $\mathrm{P} / \mathrm{AI}$ and were not offered to the multivariable model. Though opposite to what was expected, when tested independently, an observed decrease in milk yield or seeing mucous discharge were associated with a decrease in conception risk [32 vs. $23 \%(P=0.002)$ and 33 vs. $27 \%(P=0.01)$, respectively]. However, in the final model with random effects for farm and cow, these variables were no longer significant. The associations were primarily driven by 1 farm that reported a significantly higher number of these observations than the other farms.

\section{Optimal Time of Insemination}

Throughout the study 2,739 inseminations where recorded by the producers. Of those, 673 were based on a TAI protocol and were therefore not included in the calculations, leaving 2,066 AI that were based on activity. Due to inseminations that occurred at the beginning of the study and those that occurred during a period when one of the farms had a computer failure, 473 inseminations did not have a complete baseline of activity and were excluded from this analysis. This left 1,593 inseminations, of which 139 had a negative interval from the time of onset of estrus based on activity to insemination (i.e., the AI was before the activity signal) and 55 had an interval longer than $24 \mathrm{~h}$. The former inseminations were likely based on visual observation of signs of estrus (e.g., the cow was seen mounting or being mounted shortly before or during milking, before the activity data were transferred at milking and the signal processed). Of the inseminations that occurred before an activity alert, and were therefore likely based on visual detection, $25 \%$ resulted in a pregnancy; for 
inseminations that occurred past $24 \mathrm{~h}$ after activity alert, $29 \%$ resulted in pregnancies. There were 1,399 inseminations that occurred 0 to 8,8 to 16 , and 16 to $24 \mathrm{~h}$ after the activity alert and were used in the final model. Which commercial AAM system was used (which was confounded with frequency of milking) was not significant in the model. In preliminary analyses, farm had a significant effect on the odds of pregnancy. However, we observed no interaction between farm and interval to insemination. The variables that remained in the model were interval to insemination, parity, and the interaction between interval to insemination and parity, with farm and cow as random effects. For multiparous cows the mean $( \pm \mathrm{SE})$ probability of pregnancy per AI was $31.3 \pm 3.1 \%$ and was not different $(P=0.7)$ among intervals from onset of estrus to AI. For primiparous cows, AI within $8 \mathrm{~h}$ of onset of estrus was associated with 1.8 and 2.1 times greater odds of pregnancy than AI 8 to 12 or 16 to $24 \mathrm{~h}$ after onset, respectively. The predicted $\mathrm{P} / \mathrm{AI}$ for primiparous cows for each interval were $49 \pm 5.0,36 \pm 5.2$, and $32 \pm 5.5 \%$, respectively. Figure 1 depicts the association between model-predicted pregnancy risk and the interaction between the time intervals after activity monitor alert and parity.

\section{DISCUSSION}

We have shown that in a sample of freestall dairy farms representative of common management practices and reproductive performance that AAM can detect over $80 \%$ of cows in estrus within just over the length of 1 estrous cycle without interventions. However, the remaining cows would require intervention to ensure timely insemination. Cows that were anovular, multiparous, positive for PVD, or had both low BCS and lameness were less likely to be detected in estrus by AAM and inseminated by 80 DIM. Of cows that were inseminated based on an activity monitor alert, only $3 \%$ had a serum P4 concentration incompatible with estrus, which was similar to the cows bred by a TAI protocol. However, managers applied subjective criteria not to inseminate $17 \%$ of estrus events signaled by the AAM system. Among cows that were inseminated based on AAM, signs of estrus that happened to be observed by the producer were not associated with the risk of pregnancy.

On commercial farms, Fricke et al. (2014) found that only $56 \%$ of cows were detected in estrus by activity monitoring by 65 DIM. In our study, activity monitors detected $83 \%$ of cows in estrus by 80 DIM without intervention. This indicates that AAM, given the time for a full estrous cycle (in this case $25 \mathrm{~d}$ ), can effectively achieve timely first insemination for a substantial majority of cows, but also highlights that intervention such as a TAI would be needed for the remainder to achieve this goal.

The prevalence of anovular cows in this study is within the herd-level range of 5 to $45 \%$ reported by Walsh et al. (2007). However, the mean prevalence is typically 20 to $30 \%$ (Gümen et al., 2003; Lopez et al.,

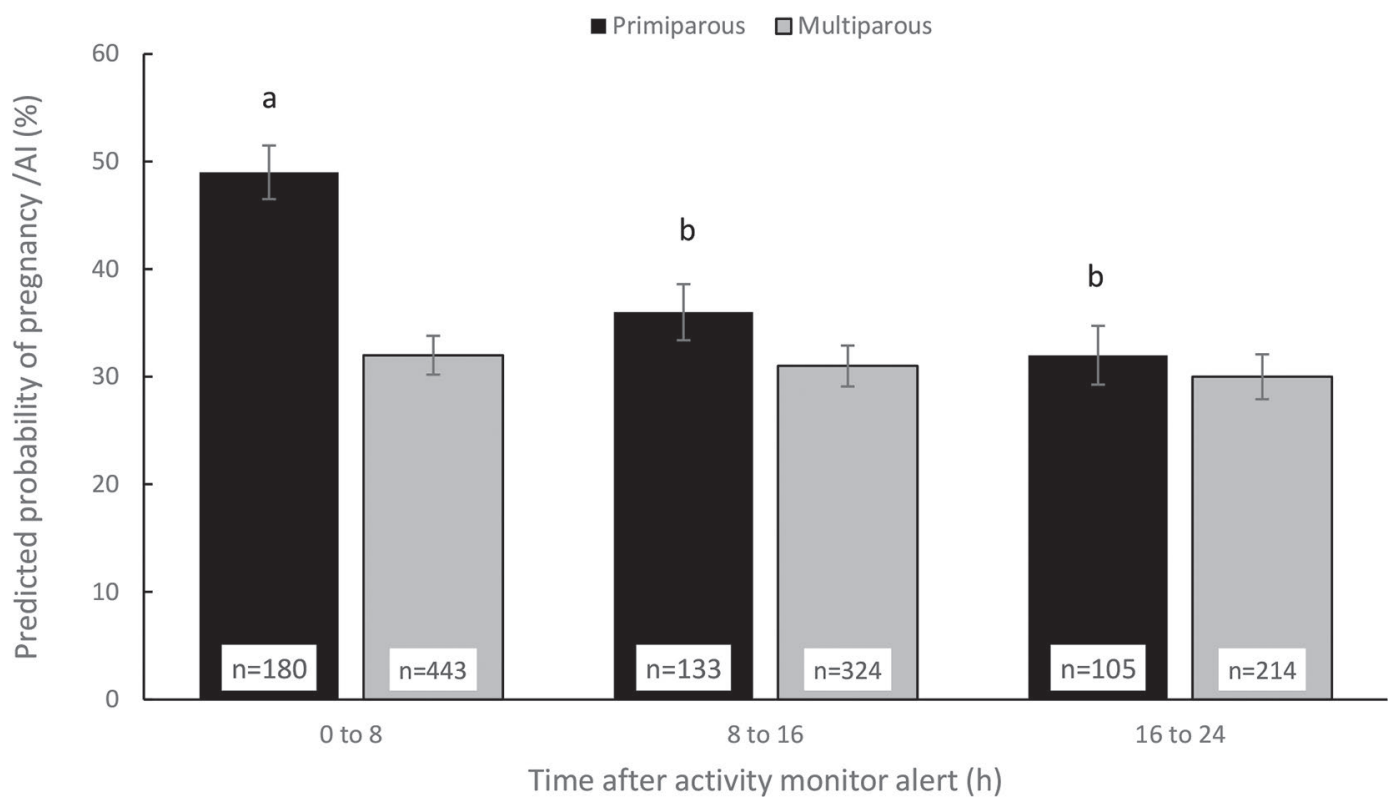

Figure 1. Predicted probability of pregnancy $( \pm \mathrm{SE})$ based on the interval from activity monitor estrus alert to AI for primiparous and multiparous cows, from a model accounting for the random effects of farm and cow. For primiparous cows, columns with different letters differ $(\mathrm{a}, \mathrm{b} ; P<0.006)$. 
2005; Walsh et al., 2007), which is much higher than we observed (9\%). This could be explained by the fact that our study was conducted in well-managed herds that had a low prevalence of lameness and few cows with low BCS, each of which are risk factors for anovular condition. As expected, cows that were anovular were 2 times less likely to be inseminated by 80 DIM.

The prevalence of PVD in our study was consistent with the 10 to $17 \%$ that has been reported by others (Barlund et al., 2008; Dubuc et al., 2010; DenisRobichaud and Dubuc, 2015). Cows diagnosed with PVD had $40 \%$ higher odds of not being detected in estrus by AAM by 80 DIM. An association between PVD and being noncyclic has been shown by Maquivar et al. (2015), who found that $44 \%$ of cows without PVD were anovular by $40 \pm 3$ DIM but $57 \%$ of untreated cows with PVD were anovular. However, we found no interaction between PVD and being anovular with respect to the probability of estrus detection by AAM by 80 DIM.

The association between low body condition and lameness has been demonstrated in numerous studies. For example, Solano et al. (2015) found that the odds of lameness were 1.6 times greater in cows with BCS $\leq 2.5$. In the present study, few cows had both low BCS and were lame at wk 7 of lactation, but these cows were more than twice as likely not to be inseminated by 80 DIM compared with well-conditioned, nonlame cows. Though this interaction had a $P$-value $=0.11$ (Table 3 ), the effect was substantial, so this term was kept in the model.

When looking at only the blood samples that came from animals that were inseminated, the proportion of animals signaled by the AAM system that had high P4 at time of insemination (therefore considered not to be in estrus) was very low and not different than the proportion with high $\mathrm{P} 4$ that were inseminated on a TAI protocol. However, the $17 \%$ of eligible cows signaled by AAM as in estrus that were not inseminated demonstrates that the producers were implementing selective insemination when looking at the list generated by the AAM system. It is possible that the producers were seeking confirmatory signs of estrus, such as vaginal mucus or behavioral indicators, and if these were absent they would not inseminate the cow. The fact that nearly half of these cows had high serum P4 supports that being the case for some cows. Other variables, such as advanced stage of lactation, history of mastitis or lameness, poor conformation, or other criteria, may have influenced managers' decisions not to inseminate certain cows even though they had not been recorded as not to be bred. Unfortunately, our data collection did not specifically capture reasons for noninsemination of cows signaled by the AAM system. Nevertheless, in- clusion of these AAM signals significantly reduced the overall specificity of the estrus alerts, and we encourage future research to explore the criteria for and effect of superimposition of exclusion factors subsequent to AAM estrus alert.

Though it was out of the scope of the present study, implementing observation of estrous behaviors in addition to AAM is likely to increase the sensitivity, but not necessarily the accuracy, of estrus detection. In the present study, cows that were not inseminated when they had an activity alert had a significantly higher risk of having high $\mathrm{P} 4$. Although the reasons for noninsemination of eligible cows were not recorded, it appears that in many cases producers correctly applied selection or confirmation criteria to AAM alarms. These apparent false-positive estrus signals might have been associated with moving cows to a new pen or nonroutine activity in the barn (e.g., hoof trimming). If these cows had been inseminated it would have increased the number of false-positives and presumably decreased $\mathrm{P} /$ AI. However, overriding the AAM indication of estrus can also have negative effects, because $57 \%$ of these cows did have low $\mathrm{P} 4$ and might have been successfully inseminated. With the addition of the noninseminated animals, the proportion accurately detected by the activity monitors (based on low serum $\mathrm{P} 4$ concentration) decreased to $91 \%$, similar to Madureira et al. (2015).

The lack of association of chance observation of increased activity, mounting, mucous discharge, or decrease in milk production or of being considered an easy insemination with $\mathrm{P} / \mathrm{AI}$ is consistent with the findings of Madureira et al. (2015), who found that secondary signs of estrus had no influence on pregnancies per AI based on AAM.

The finding that primiparous cows should be inseminated earlier after AAM alert compared with multiparous cows is novel. This result differs from Stevenson et al. (2014), who found that pregnancy was maximized for primiparous cows when inseminated between 13 and $16 \mathrm{~h}$ after activity alert, but among multiparous cows pregnancy risk did not differ between the 0 - and 12 -h intervals. Their observation of the tendency for primiparous cows to ovulate slightly earlier than multiparous cows generally fits with our data. Stevenson et al. (2014) used a different AAM system compared to the 2 in our study, but otherwise we do not have an explanation for the divergence between our results and theirs. Our optimal timing of insemination for primiparous cows fits into the wide optimal range of 5 to $17 \mathrm{~h}$ after increased pedometer activity (Maatje et al., 1997; Roelofs et al., 2006). The time from onset of estrus based on AAM to ovulation $(\sim 30 \mathrm{~h})$ and the optimal timing of AI relative to ovulation (12 to $24 \mathrm{~h}$ before) are well established, and the optimal timing of AI rela- 
tive to the onset estrus based on AAM consistently falls in the window of 5 to $17 \mathrm{~h}$ (Roelofs and van Erp-van der Kooij, 2015). Our result that the conception risk for multiparous cows did not change up to $24 \mathrm{~h}$ after an activity monitor alert agrees with the findings of Foote (1978) and Nebel et al. (1994), who found that once daily insemination could achieve similar $\mathrm{P} / \mathrm{AI}$ as AI twice a day, although with $\mathrm{P} / \mathrm{AI}$ of approximately $31 \%$ in multiparous cows in the present study $\mathrm{P} / \mathrm{AI}$ was probably not maximized.

Our results provide a benchmark for expectations of AAM relative to the need for interventions, such as TAI, to achieve targets for timely first AI. Conducting studies such as this on commercial farms provides greater statistical power and generalizability of the results than smaller studies in more controlled research herds. Limitations of using commercial farms include not having all information about management decisions to inseminate a cow or not when flagged by the AAM system. Future studies should investigate the utility and incremental gains in performance from the addition of other estrus detection methods to AAM. Another limitation to our study is that cows were not systematically confirmed as in estrus when they were signaled by the activity monitor and inseminated. However, for a subset of these AI $(\mathrm{n}=445)$, only $3 \%$ of cows that were flagged by the activity monitor and inseminated had high P4 at insemination and, therefore, were not in estrus.

The activity monitoring systems differed in how they detected cows in estrus and the raw activity data that they produced. Nevertheless, we did not detect effects of, or interactions with, the AAM system for any of the outcomes measured. Though Afimilk and SCR produced activity data in 8- and 2-h blocks, respectively, our interest was when the AAM system actually flagged cows in estrus and the manager could take action based on that alert. This difference was overcome by evaluating the interval from when the cow was flagged in estrus by the AAM system and not from the exact moment signs of estrus were displayed; the former reflects the reality of use of the systems. Future research may consider whether newer AAM systems that provide data and alarms in near-real time (i.e., data are not only transferred at milking) change or narrow the optimal timing of AI. Optimized timing of AI would have to be balanced against the practicality of performing AI several times throughout the day and night.

\section{CONCLUSIONS}

Activity monitors can identify over $80 \%$ of animals for insemination between 55 and 80 DIM, but intervention such as TAI would be required for the remainder. Iden- tification and treatment of PVD, anovular condition, and lameness may improve estrus detection by AAM; these effects should be quantified in future studies. Activity monitors are effective at identifying animals that have low $\mathrm{P} 4$ at insemination. Accuracy can apparently be improved with managers' discretion about insemination of cows signaled as in estrus by AAM, but specific signs associated with higher P/AI were not identified. The effect of selection criteria for AI following AAM estrus alert on performance of this management tool should be specifically investigated in future studies. Given a decision to employ AAM as a primary tool for reproductive management, primiparous cows should be inseminated between 0 to $8 \mathrm{~h}$ after they are signaled in estrus by the activity monitor to maximize the probability of pregnancy. Conversely, we found no difference in the odds of pregnancy for the multiparous cows inseminated up to $24 \mathrm{~h}$ after the activity monitor alert. Prioritizing the insemination of first-lactation cows to achieve intervals of $<8 \mathrm{~h}$ from the AAM signal has the potential to increase the probability of pregnancy. However, with divergent results between this study and another large field study, further research is needed to confirm the optimal timing of AI for primiparous cows or the factors that influence the optimal timing. We also underline that the 8-h intervals of AI timing were imposed by the structure of our data from 2 of the 4 farms and do not necessarily reflect the biological optimum. Again, given a decision to employ AAM as a primary tool for reproductive management, for multiparous cows, there appears to be more flexibility to inseminate up to $24 \mathrm{~h}$ after the onset of estrus based on AAM. However, AAM may not maximize the probability of pregnancy per AI, particularly in multiparous cows. Therefore, we suggest that performing AI based on AAM once per day may be acceptable for multiparous cows, but that inseminating based on activity data at least twice per day may improve pregnancy per AI in primiparous lactating dairy cows.

\section{ACKNOWLEDGMENTS}

Funding for this study was provided by Dairy Farmers of Ontario, Mississauga, Ontario, Canada.

\section{REFERENCES}

Abramson, J. H. 2011. WINPEPI updated: Computer programs for epidemiologists, and their teaching potential. Epidemiol. Perspect. Innov. 8:1.

Aungier, S. P. M., J. F. Roche, M. Sheehy, and M. A. Crowe. 2012. Effects of management and health on the use of activity monitoring for estrus detection in dairy cows. J. Dairy Sci. 95:2452-2466.

Barlund, C. S., T. D. Carruthers, C. L. Waldner, and C. W. Palmer 2008. A comparison of diagnostic techniques for postpartum endometritis in dairy cattle. Theriogenology 69:714-723. 
Broes, A., and S. J. LeBlanc. 2014. Comparison of commercial progesterone assays for the evaluation of luteal status in dairy cows. Can. Vet. J. 55:582-584.

Denis-Robichaud, J., and J. Dubuc. 2015. Determination of optimal diagnostic criteria for purulent vaginal discharge and cytological endometritis in dairy cows. J. Dairy Sci. 98:6848-6855.

Dubuc, J., T. F. Duffield, K. E. Leslie, J. S. Walton, and S. J. LeBlanc. 2010. Definitions and diagnosis of postpartum endometritis in dairy cows. J. Dairy Sci. 93:5225-5233.

Edmonson, A. J., I. J. Lean, L. D. Weaver, T. Farver, and G. Webster. 1989. A body condition scoring chart for Holstein Dairy Cows. J. Dairy Sci. 72:68-78.

Foote, R. H. 1978. Time of artificial insemination and fertility in dairy cattle. J. Dairy Sci. 62:355-358.

Fricke, P. M., J. O. Giordano, A. Valenza, G. Jr. Lopes, M. C. Amundson, and P. D. Carvalho. 2014. Reproductive performance of lactating dairy cows managed for first service using timed artificial insemination with or without detection of estrus using an activitymonitoring system. J. Dairy Sci. 97:2771-2781.

Gümen, A., J. N. Guenther, and M. C. Wiltbank. 2003. Follicular size and response to Ovsynch versus detection of estrus in anovular and ovular lactating dairy cows. J. Dairy Sci. 86:3184-3194.

Hawk, H. W. 1987. Transport and fate of spermatozoa after insemination of cattle. J. Dairy Sci. 70:1487-1503.

Holman, A., J. Thompson, J. E. Routly, J. Cameron, D. N. Jones, D. Grove-White, R. F. Smith, and H. Dobson. 2011. Comparison of oestrus detection methods in dairy cattle. Vet. Rec. 169:47.

Leutert, C., X. von Krueger, J. Plöntzke, and W. Heuwieser. 2012. Evaluation of vaginoscopy for the diagnosis of clinical endometritis in dairy cows. J. Dairy Sci. 95:206-212.

Lopez, H., D. Z. Caraviello, L. D. Satter, P. M. Fricke, and M. C Wiltbank. 2005. Relationship between level of milk production and multiple ovulations in lactating dairy cows. J. Dairy Sci. 88:27832793.

López-Gatius, F., M. Lopez-Bejar, M. Fenech, and R. H. F. Hunter. 2005. Ovulation failure and double ovulation in dairy cattle: Risk factors and effects. Theriogenology 63:1298-1307.

Maatje, K., S. H. Loeffler, and B. Engel. 1997. Optimal time of insemination in cows that show visual signs of estrus by estimating onset of estrus with pedometers. J. Dairy Sci. 80:1098-1105.

Madureira, A. M. L., B. F. Silper, T. A. Burnett, L. Polsky, L. H. Cruppe, D. M. Veira, J. L. M. Vasconcelos, and R. L. A. Cerri. 2015. Factors affecting expression of estrus measured by activity monitors and conception risk of lactating dairy cows. J. Dairy Sci. 98:7003-7014.
Maquivar, M. G., A. A. Barragen, J. S. Velez, H. Bothe, and G. M. Schuenemann. 2015. Effect of intrauterine dextrose on reproductive performance of lactating dairy cows diagnosed with purulent vaginal discharge under certified organic management. J. Dairy Sci. 98:3876-3886.

Michaelis, I., E. Hasenpusch, and W. Heuwieser. 2013. Estrus detection in dairy cattle; changes after the introduction of an automated activity monitoring system. Tierarztl. Prax. Ausg. G Grosstiere Nutztiere 41:159-165.

Nebel, R. L., W. L. Walker, M. L. McGilliard, C. H. Allen, and G. S. Heckman. 1994. Timing of insemination of dairy cows: Fixed time once daily versus morning and afternoon. J. Dairy Sci. 77:31853191.

Roelofs, J. B, and E. A. Graat., EMullaart, N. M., W. Soed, Voskamp-Harkema, and K. Kemp. 2006. Effect of time of insemination relative to ovulation on fertilization rates and embryo characteristics in spontaneous dairy cattle. Theriogenology 66:2173-2181.

Roelofs, J. B., and E. van Erp-van der Kooij. 2015. Estrus detection tools and their applicability in cattle: recent and perspectival situation. Anim. Reprod. 12:498-504.

Saint-Dizier, M., and S. Chastant-Maillard. 2012. Towards an automated detection of oestrus in dairy cattle. Reprod. Domest. Anim. 47:1056-1061.

Solano, L., H. W. Barkema, E. A. Pajor, S. Mason, S. J. LeBlanc, J. C. Zaffino Heyerhoff, C. G. R. Nash, D. B. Haley, E. Vasseur, D Pellerin, J. Rushen, A. M. de Passillé, and K. Orsel. 2015. Prevalence of lameness and associated risk factors in Canadian HolsteinFriesian cows housed in freestall barns. J. Dairy Sci. 98:6978-6991.

Sprecher, D. J., D. E. Hostetler, and J. B. Kaneene. 1997. A lameness scoring system that uses posture and gait to predict dairy cattle reproductive performance. Theriogenology 47:1179-1187.

Stevenson, J. S., S. L. Hill, R. L. Nebel, and J. M. DeJarnette. 2014 Ovulation timing and conception risk after automated activity monitoring in lactating dairy cows. J. Dairy Sci. 97:4296-4308.

Stevenson, J. S., J. R. Pursley, H. A. Garverick, P. M. Fricke, D. J. Kesler, J. S. Ottobre, and M. C. Wiltbank. 2006. Treatment of cycling and noncycling lactating dairy cows with progesterone during Ovsynch. J. Dairy Sci. 89:2567-2578.

Walker, W. L., R. L. Nebel, and M. L. McGilliard. 1996. Time of ovulation relative to mounting activity in dairy cattle. J. Dairy Sci. 79:1555-1561.

Walsh, R. B., D. F. Kelton, T. F. Duffield, K. E. Leslie, J. S. Walton, and S. J. LeBlanc. 2007. Prevalence and risk factors for postpartum anovulatory condition in dairy cows. J. Dairy Sci. 90:315-324. 